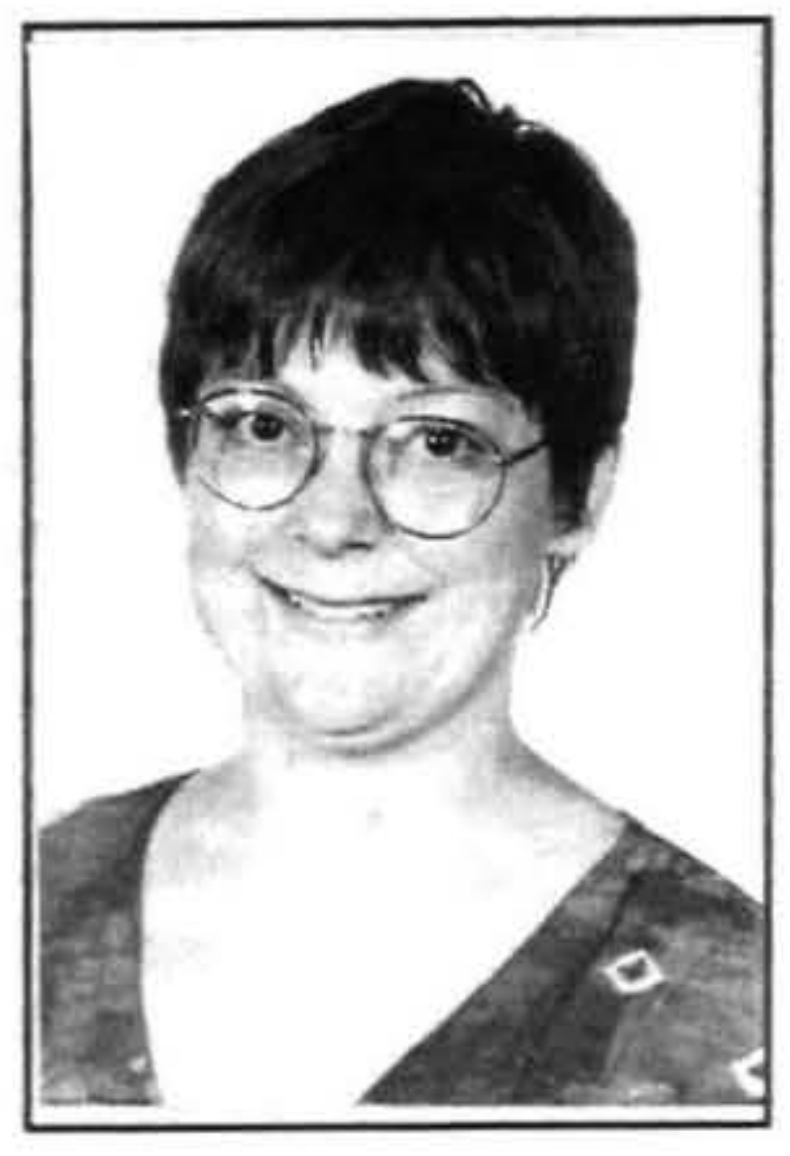

\title{
SEGMENTATION THEORY AND \\ THE NEW ZEALAND \\ LABOUR MARKET 1
}

\author{
Chandra Dixon \\ University of Auckland
}

\begin{abstract}
Segmented Labour Market (SLM) analysis by no means enjoys a unified or clearly structured theoretical base. Analysts emphasise a variety of factors in their explanations of the existence of inequalities in the labour market. This paper uses an industry approach to evaluate inequalities. A case study of two industries is used - the plastics industry and the hotel/ restaurant industry - on the assumption that each will exhibit characteristics defining them as primary and secondary sectors respectively. The paper focuses on indicative findings of both inter-industry and intra-industry labour market segmentation. The approach taken is part of a broader doctoral thesis, which seeks to establish a viable SLM paradigm within the context of post-ECA New Zealand labour market conditions.
\end{abstract}

This research grew out of a strong suspicion, shared by many others, that the labour market possesses inequalities which run deeper than can be explained by 'market imperfections'. With an interest in seeing whether or not structural patterns of inequality exist, I began to study the literature on dualism, or segmented labour market (SLM) analysis. ${ }^{2}$ SLM analysis gained popularity in the USA in the early seventies as a means to address the issue of poverty, particularly the existence of urban ghettoes and the unemployment and underemployment of black Americans. It has since developed as a body of thought which seeks generally to understand inequality in the labour market.

The precept of SLM theory, as the term suggests, is that the labour market is divided into segments. Most notably, and where the terms dualism and duality enter the fray, the labour market is characterised by two distinct segments the primary and secondary sectors. ${ }^{3}$ In general, the sectors are distinguished in terms of 'good' and 'bad' jobs (although it is impracticable to define jobs as wholly good or bad) - determined by the degree of job stability, wages and working conditions, access to promotional opportunities, on-the-job training and the existence of hierarchical job ladders. In addition, the sectors are distinguished by the composition of employees and employee characteristics. Moreover, movement of workers between the primary and secondary sectors is minimal; that is, a worker employed in the secondary sector will have difficulty in gaining access to the primary sector. Terms such as the 'balkanisation' of labour thence arise, implying that the labour market is comprised of non-competing groups. ${ }^{4}$

SLM theory views inequality in the labour market as a complex problem. At root, it is a structural phenomenon, and in this SLM analysis holds common ground with radical theory. Piore notes that "...segmentation is...consistent with the aesthetics of Marxian economics, and it is, therefore, no accident that many of its chief exponents are radical economists. ${ }^{5}$ Inequality is further reinforced by the location of agents within the primary and secondary structures. ${ }^{6}$ Here, in contrast to the radical position, SLM analysis does not focus solely on class dynamics to explain the existence of inequality in the labour market. Likewise, whilst SLM analysts see women's place and role in the labour market as being a strong indicator of the discrimination inherent in the labour market process, they do not emphasise the sexual division of labour per se. Rather, a number of factors are emphasised, such as gender, ethnicity, class, education and age. Although it is acknowledged that often these variables are interdependent, SLM theory does not use any one of these elements as a springboard to explaining other forms of inequality.

That the SLM approach is multifarious need not be a disadvantage. Indeed, it could be argued that the many different emphases included within the literature illustrate the complexities of the labour market structure and processes. As Peck argues: "Segmentation theory seems destined never to exhibit the analytical purity of the orthodox, perfectly-competitive model (or indeed of some of the more dogmatic Marxist approaches). In stressing the complexity of labour market processes and outcomes, however, segmentation theory has a strong purchase on the concrete realities of the labour market. ${ }^{p}$

\section{Labour market segmentation}

Ryan provides a useful foundation for clarifying the SLM 
approach, by distinguishing between pre-market and inmarket segmentation. ${ }^{8}$ Pre-market segmentation arises from discrimination based on sociological factors such as gender, ethnicity, age and class, and can thus be linked with social stratification. Sociological factors lead to differences between potential employees at the point of labour market entry. Any single factor, or a combination of these factors, may differently affect a person's educational opportunities, resulting in different knowledge and skill levels at point of entry. In other instances gender, ethnicity, class and age may be elements which lead to unqualified discrimination at point of entry. For example, in regard to gender, role stereotyping might preclude women from jobs or 'good' jobs on the basis of motherhood. Pre-market segmentation is a phenomenon recognised by economists and social scientists of widely differing persuasions ${ }^{9}$, and is not confined to those holding values of equality in the labour market. ${ }^{10}$ According to SLM analysts, primary and secondary labour markets are distinguishable, through pre-market segmentation, by the composition of their respective workforces. In particular, women and disadvantaged ethnic minorities will be overrepresented in the secondary sector. In this, SLM analysis holds common ground with other theories of the labour market.

Primary and secondary labour markets are further distinguishable through in-market segmentation. It is here where SLM theory sets itself apart from competing theories. Ryan comments that " $[t]$ he near consensus among economists concerning the relevance of segmentation vanishes...when we move from the pre- to the in-market variant. ${ }^{11}$ In-market segmentation occurs where workers of equal potential are further differently treated once employment is obtained, due to the the different structures of primary and secondary labour markets.

The primary labour market is characterised by job stability, which manifests itself through a number of in-market variants. One is the internal labour market. This consists of an institutionalized promotional structure, which is accompanied by clear job differentiation and a bureaucratised wage structure. Once a worker has gained entry to the firm, s/he has the opportunity to climb the promotional ladder, and jobs further up the ladder are appointed to workers already inside the firm. It is therefore difficult for potential employees to gain access to employment at any other but the bottom rung of the ladder.

An intrinsic component of the internal labour market structure is workplace training. Employers in the primary sector invest in firm-specific training as part of the promotional process. The result of hierarchical job ladders and workplace training is a high degree of stability for both employer and employee which is peculiar to the primary labour market. For the employee, wages and working conditions improve with promotion and the risks entailed in seeking employment elsewhere become greater, as the training received is firm-specific. For the employer, the investment entailed in providing training is offset by a higher probability of employee retention.

Within the primary labour market, analysts have identified a two tiered structure which, whilst not undermining the broader primary/secondary dichotomy, provides what may be a useful qualification in the process of applying SLM theory to practice. The tiers have been defined in terms such as the 'upper' and 'lower' tiers ${ }^{12}$ of the primary labour market. The upper tier is comprised of skilled and some semi-skilled jobs, so contains managerial, professional and technical workers. In contrast, the lower tier is comprised of unskilled and some semi-skilled jobs which "generally involve routinized, repetitive tasks, specific supervision, and formalized work rules. ${ }^{.13}$ Whilst both tiers form part of the primary sector, thus both exhibiting its characteristics, the structures within which the two tiers operate are distinct. Workers in the upper tier bring general skills to their jobs through higher educational qualifications, which they apply in their given job. They experience high degrees of autonomy and opportunities for promotional and wage mobility. Stability and job attachment are therefore consolidated.

The lower tier, however, possesses quite a different structure. Workers rarely bring general skills to their job, and rarely learn such skills whilst employed. Rather, workplace training is job specific, leading to stability because skills acquired are not general enough to be transferable to a significantly better job elsewhere. Thus, the lower tier may exhibit patterns similar to the secondary sector in that the job ladder may have few rungs. Mobility may be horizontal rather than vertical. However, in that the employer invests in workplace training, be it for specific routinized tasks, wages and working conditions should be better than those of secondary sector workers, because they should reflect a desire for worker retention resulting from training investment. Adnett summarises the position of workers in the lower tier thus:

[T]he 'good' jobs are better than secondary labour market jobs but not that much better, and many manual workers in 'good' jobs are still employed in tasks which underutilise their talents. Few unskilled and semiskilled workers can ever cross the manual-technician/ supervisory-management divide. ${ }^{14}$

In contrast to the primary labour market, the secondary labour market contains features pertaining to 'bad' jobs, and is characterised by instability and underemployment. Due to pre-market segmentation, disadvantaged groups are over-represented in the secondary sector, and, as Wachter notes, it "contains the great bulk of those with low education as well as those who did not succeed in translating their higher education into higher incomes." 15 This is an important point, in that workers in the primary and secondary sectors can not be distinguished simply by differences in skill level, at least not at point of labour market entry.

In-market segmentation further reinforces the differences 
existing between primary and secondary sectors. The latter can generally be considered an unstable sector. There is minimal job attachment, few promotional incentives, the work is often casualized, wages are low and working conditions are relatively poor. There is no internal labour market; the sector exhibits a comparatively flat job structure in which jobs are predominantly unskilled and labour intensive. In this, the employer has little incentive to institute workplace training programmes. On departure, an employee is easily replaced with minimal costs to the employer in training a replacement. The only attachment a worker has to her/his job is the wage, which is low and has minimal prospects of significantly increasing. Other than this, lack of career prospects in the secondary firm results in a minimal overall attachment to the job. Thus, the theory suggests that turnover is high. A worker will change jobs or seek altemative jobs more frequently than will a primary sector worker. However, due to in-market characteristics of the primary sector, job movement for a secondary sector worker will by and large remain within the secondary market.

The above arguments, then, comprise some of the common threads running through SLM literature. Two distinct labour markets exhibit different structural characteristics, the concentration of agents within each structure differs, and mobility from the secondary to the primary labour market is minimal. As is always the case, the question then arises as to how, and how well, this theoretical picture can be applied to real conditions.

\section{Empirical evidence}

This paper uses an industry approach to test the plausibility of the theory, comparing the plastics and the hotel/restaurant/tearoom industries. Reasons as to why I have taken an industry approach are twofold. Firstly, these particular industries were chosen because I strongly suspect that, at an industry-wide level, the plastics and hotel/restaurant/ tearoom industries might exhibit patterns of a primary and secondary labour market respectively. This hypothesis is based on several assumptions. The service industry in general is dominated by women. This does not automatically confirm the existence of segmentation, because the primary and secondary markets are by and large structural divisions distinguishable by job characteristics. However, pre-market segmentation suggests that certain agents are concentrated in different structural locations, and that women are more likely to be in 'bad' or secondary jobs. With respect to in-market segmentation, the two industries might also differ. For example, the plastics industry is part of the manufacturing sector, so the operation of firms in the industry is reliant on the use of large scale fixed capital, in the form of technology and machinery. One might therefore expect to find primary labour market characteristics, in that an employer might be reliant on an employee's specific skills in relation to the machinery used. Accordingly, one might also find job specificity. This may be in contrast to the hotel/restaurant/tearoom industry. Here, there is little reliance on high cost machinery, and the work is comparatively labour intensive.

The second reason for taking an industry approach is more general, but very important to the wider research. An industry approach has the advantage of providing a relatively wide lens through which to view labour market inequalities. Whilst my hypothesis is that structural inequalities may be discerned across the two industries as a whole, I also suspect that if segmentation exists, it is more complex - elements of segmentation will not only exist in an inter-industry comparison, but within each industry also. An industry approach, then, is able, in the first instance, to view possible segmentation broadly, and to also encompass a study of possible intra-industry segmentation.

In order to test the theory's viability, confidential written questionnaires were sent to 1000 workers, 500 in the plastics industry and 500 in the hotel/restaurant/tearoom industry. One should keep in mind three important qualifications when interpreting the resulting data. Firstly, the survey was confined to the Auckland region, so may only reflect patterns in that region. Secondly, as seems common with evidence gathering exercises in this area, the overall response rate was $27 \%$, so the findings can only be judged as indicative. Thirdly, only unionized workers were surveyed, which again may not paint the full picture of labour market extremities. 16

The following sketches the extent to which the theory might be plausibly adopted, highlighting some, but by no means all of the variables pertaining to SLM analysis. It is important to note that as work in progress, the picture is still very much in sketch form.

Unsurprisingly, gender distribution provides the clearest indication that pre-market segmentation exists at an industry level. Overall, the number of male and female respondents was relatively even, but gender representation within each industry is significantly different. Within plastics, $20 \%$ of respondents were women, whilst women comprised $68 \%$ of the hotel/restaurant/tearoom respondents. Furthermore, amongst respondents overall there is no significant gender difference in skill levels at point of labour market entry. So the gender composition of each industry must be put down to other factors. It may simply be a case of unqualified discrimination; it might be that the hotel/restaurant/tearoom industry contains a lot of casualized and part time work. Here we might assume that some women have commitments other than paid work - it is common knowledge that women are still the main care givers in the unpaid workforce, for example.

In that so few women respondents are employed in the plastics industry, and so many in the hotel/restaurant/ tearoom industry, we might take this as evidence of interindustry segmentation. As noted, though, the predominance of women in an industry does not confirm segmentation on the basis of primary and secondary sectors, which are defined by in-market variables pertaining to jobs. 
Evidence of pre-market segmentation is not enough to claim SLM theory as plausible. However, the chances of finding in-market segmentation are greatly enhanced where one finds evidence of pre-market segmentation, due to agency concentration reinforcing structural differences.

Turning to in-market variants, in some cases there is evidence to confirm that SLM theory might be useful in explaining structural inequalities. The first variant suggesting the existence of industry segmentation is to do with the nature of work. $98 \%$ of plastics respondents work fulltime, whilst only $38 \%$ of hotel/restaurant/tearoom respondents work full-time. It may be argued that full-time work will lead to a greater degree of job attachment, due to one's job forming a large part of one's life. It may therefore be argued that the high rate of part-time work in the hotel/ restaurant/tearoom industry indicates underemployment and a lesser degree of job attachment, in which case secondary labour market characteristics are clearly displayed. Moreover, there is a strong relationship between the industry in which respondents are employed and job permanence. For example, $26 \%$ of hotel/restaurant/tearoom respondents are in casual work, compared to less than $1 \%$ of plastics workers.

In terms of the skill structure in each industry, indications are again that industry segmentation exists. Respondents' occupations were categorized in to skilled, semi-skilled, unskilled, and supervisory positions. Leaving out respondents categorized as supervisors ${ }^{17}$, skill level patterns are shown in table 1.

\section{Table 1. Industry by skill level}

\begin{tabular}{lll}
\hline & Plastics & $\begin{array}{l}\text { Hotel/Restaurant/ } \\
\text { Tearooms }\end{array}$ \\
\hline Skilled & $22 \%$ & $13 \%$ \\
Semi-Skilled & $33 \%$ & $6 \%$ \\
Unskilled & $37 \%$ & $64 \%$ \\
\hline
\end{tabular}

Source: author survey, May 1994

Indications are that within plastics there is a reasonably balanced skill hierarchy, whereas the hotel/restaurant/ tearoom industry exhibits a comparatively flat structure in which unskilled work clearly predominates. On the one hand then, we have features of a primary labour market, and on the other we have features of a secondary labour market.

A qualification has to be considered here, in terms of how skill is constructed. The Engineers' Union provides clear definitions of what constitutes a skilled, semi-skilled, and unskilled job. Interestingly, these accord to SLM theory of a primary labour market, in that they are defined in terms of job specificity. Unskilled jobs include process workers and factory hands, while semi-skilled jobs are those which involve more specialized knowledge of machinery - machine operators, therefore, are defined as semi-skilled.
Skilled positions require more specialized knowledge and training again - toolmakers, fitters and turners are defined as skilled workers.

In contrast, the Service Workers' Union does not explicitly categorize jobs according to skill, so the results in table 1 have been constructed, something which has been done cautiously in view of the contention involved with such categorization. The skilled category is comprised predominantly of chefs, these jobs requiring specialized training and knowledge. In keeping with SLM propositions, the unskilled category is that in which there are no specialized skills required for the job at hand. Regardless of skills brought to the job, the work involved does not require in depth training or specialized knowledge. This being the basis for categorization, many positions in this industry can be defined as unskilled - kitchenhands, barpersons, waiters/waitresses and porters are all unskilled positions. There are inherent dangers in this of course. Waiting work is considered to be higher in the pecking order of the service industry than kitchenhand work, and waiting itself may be highly variable. One worker may need a knowledge of silver service and another need not. In this case, an employer may have more interest in retaining the former, which may be reflected in wages and working conditions. These problems, then, are acknowledged, although at the end of the day categorizations must be applied in order that comparisons can be made. On the basis of these categorizations, the two industries display contrasting characteristics of primary and secondary labour markets, with a relatively even distribution of skill levels on the one hand and a flat structure with a large pool of unskilled jobs on the other.

Workplace training is another theoretical indicator of inmarket segmentation. Comparing the two industries for this variable, we find that $48 \%$ of plastics workers and $23 \%$ of hotel/restaurant/tearoom workers have received workplace training in their current job. Instances are therefore more than two to one. However, workplace training is a strong theoretical indicator of a primary labour market, in which case $48 \%$ may not be a startling rate. In an industry comparison, though, there is a clear contrast, so in a relative sense plastics again exhibits primary labour market characteristics.

In terms of workplace training being reflected in in-firm mobility, however, the weakest link appears in the data to date. There is little difference here between the two industries, with $34 \%$ of plastics respondents and $38 \%$ of hotel/restaurant/tearoom respondents having had other job titles for their current employer. This suggests that while in other instances the plastics industry can be seen to generally exhibit primary labour market characteristics, movement within an internal labour market does not strongly apply, despite this being a central component of SLM theory.

The other initial finding which weakens the applicability of the theory is the issue of longevity of service. Here too 
there is almost no difference between the industries, with $70 \%$ of plastics respondents and $69 \%$ of hotel/restaurant/ tearoom respondents having worked for their current employer for more than three years. Amongst the latter respondents there is little evidence of movement in and out of the labour market, another component emphasised in the theory.

With respect to these last two variables, three possible explanations can be forwarded. The first is simply that SLM theory is not a viable tool for explaining inequalities in the labour market. After all, these two components are central to the SLM thesis. The second explanation, which may be more fruitful, is that SLM theory may be used as a tool to explain structural inequalities, but it needs to be modified in order to be appropriate to the current New Zealand context. More specifically, the theory must be set within broader economic parameters. The theory was developed in a period of relative economic prosperity in the USA, despite which black Americans were disproportionately unemployed and underemployed. The current New Zealand context is quite different and continues to be characterized by features of recession, in particular high unemployment. This may explain the aforementioned discrepancies. In regard to respondents' length of service in the hotel/restaurant/tearoom industry, job scarcity will increase the risks to these workers in seeking altemative employment. Coupled with this is government regulation on the unemployment benefit, whereby a person is unable to claim a benefit for six months after quitting a job. This would largely preclude practical application of the SLM proposition that workers in a secondary sector move in and out of employment on a frequent basis. Recessionary characteristics may also explain the lack of in-firm mobility in the plastics industry. Job scarcity may act as an insurance policy for an employer, in that retention of a stable workforce with in-firm skills is easier to achieve in a period of scarcity, lessening the need to offer promotional incentives.

The third explanation is one which goes hand in hand with the second, assuming that SLM theory is a plausible mechanism by which to study labour market inequalities. This is that the theory must be analyzed on a number of different levels. Thus far, early indications of this research are that, in general, an industry comparison clearly shows some evidence of segmentation, while being weaker in other variables. Given that there is a definite gender division, that the skill hierarchies in the two industries are different, that the plastics industry is dominated by fulltime permanent work, and that instances of workplace training differ markedly between the two sectors, we have signs which suggest that SLM theory may be plausibly adopted. However, in other instances an industry comparison is less fruitful. This may be simultaneously the problem and the merit of SLM analysis. The theory does not explicitly indicate where one might locate primary and secondary labour markets. Its problem lies in knowing where to find consistent patterns, but its merit lies, I think, in its complexity, which is why it has, as Peck claims, 'a strong purchase on the concrete realities of the labour market.' (Peck, 1989: 138)

Evidence of the need to look at the SLM model from a multi-level perspective can be seen in initial findings of ethnic segmentation patterns. Maori and Pakeha representation in the two industries is relatively balanced, the only glaring differential being that $78 \%$ of Pacific Island respondents are in the plastics industry. However, while this is the only marked difference in an inter-industry comparison, a look at skill levels across both industries does present evidence of demarcation. For example, looking at occupations which are categorized as skilled, the picture appears thus - Pakeha are $67 \%$ of overall respondents, and are $91 \%$ of skilled workers, Maori are $14 \%$ of respondents and are 5\% of skilled workers, and Pacific Islanders are $15 \%$ of respondents and only $2 \%$ of skilled workers. So whilst initial indications do not show patterns of industry segmentation in terms of ethnic representation (with the exception of Pacific Island respondents), the skill levels at which different ethnic groups are represented do differ markedly in proportion to their overall representation. This pattern not only provides evidence of the interaction between structure and agency in the segmentation process, but also provides evidence of the need to analyze segmentation from both an inter- and intra-industry perspective.

\section{Future research}

The next step is to increase the complexity of the research, taking as a base the broad hypothesis that segmentation is in many respects visible at an industry level, but may be operating more clearly in other cases at different levels, within industries and even within individual enterprises. Within this multi-tiered framework, the many variables which comprise SLM analysis will be researched, including those introduced above, and others such as wages, working conditions, previous employment history, and so forth. This would provide a complex picture, but I suspect that this will be the strength of SLM analysis.

The labour market is too complex to be viewed as just another commodity market, and SLM theory might be useful in illustrating this. However, it is imperative that it is applied in the context of current political and economic conditions. For this reason, a broader study must encompass activities of the state. This is particularly important in light of what the state calls the 'deregulation' of the labour market. Bowie explains that "....in a country with a relatively high degree of legal regulation in the sense that a high proportion of the workforce is blanketed by instruments including provisions covering such areas as minimum wages, redundancy packages, equal pay and pay increments, then the distinction between primary and secondary sectors may become more blurred." 18 Given the state's re-regulation of the labour market over recent years, one would expect that segmentation in all its complexity has intensified in New Zealand. 


\section{References}

Adnett, Nick 1989 Labour market policy Longman, London

Berger, Suzanne and Michael J. Piore 1980 Dualism and discontinuityin industrial societies Cambridge University Press, New York

Bowie, R. 1983 The dual labour market. In Easton, B. (ed.) Studies in the labour market New Zealand Institute of Economic Research, Wellington

Brosnan, Peter, David Rea and Moira Wilson 1991 Labour market segmentation and the state: the New Zealand experienceWorking Paper, Industrial Relations Centre, Victoria University, Wellington

Cain, Glen G. 1976 The challenge of segmented labor market theories to orthodox theory: a survey Journal of Economic Literature 14: 1215-1257.

Edwards, Richard C., Michael Reich and David M. Gordon (eds.) 1975 Labor market segmentation D.C. Heath, Lexington, Mass.

Gordon, David M. 1972 Theories of poverty and underemployment Lexington Books, Lexington, Mass.

Peck, Jamie A. 1989 Labour market segmentation theory Labour and Industry 2 (1) 119-143.

Piore, Michael J. 1983 Labour market segmentation: to what paradigm does it belong? American Economic Review 73: 249-253

Piore, Michael J. 1975 Notes for a theory of labor market stratification. In Edwards, Richard, et.al., Labor market segmentation : 125-150.

Ryan, Paul 1981 Segmentation, duality and the internal labour market. In Frank Wilkinson (ed.) The dynamics of labour market segmentation Academic Press Inc., London

Wachter, Michael L. 1974 Primary and secondary labor markets: a critique of the dual approach Brookings Papers on Economic Activity 3: 637-680.

\section{Notes}

${ }^{1}$ This paper is a general introductory overview of what the author hopes will eventually become a doctoral thesis. I extend my grateful thanks to both the Engineers' Union and the Service Workers' Union for their invaluable assistance with the empirical component of this research, particularly Shiralee Strange, Bill Newson, and Ahlene McKee. I am grateful also to the many people who offered useful comments on the original draft.

2 SLM theory and Dualism are closely connected theoreti- cal approaches, the latter term usually describing the theory's early phase. Within the body of literature, the terms are at times used synonymously. Both highlight the existence of primary and secondary labour markets. This author chooses to use the term SLM to address labour market issues, on the presumption that it gives a more complex picture, recognising primary and secondary distinctions within and between sectors more clearly than the term dualism. The reader should be aware, however, of the interchangeability of the terms.

3 The terms 'primary' and 'secondary' to explain labour market differentiation do not strictly correlate to the concepts primary, secondary and tertiary used by economists to distinguish between sectors of production.

4 This concept is not restricted to SLM analysis. John Stuart Mill identified the existence of non-competing groups in his writings, which have since been adopted by neo-classicists.

5 Piore, (1983: 250).

${ }^{6}$ See Brosnan et.al for a useful exposition on the complexities of structure and agent in the segmentation process.

${ }^{7}$ Peck, (1989: 138).

${ }^{8}$ Ryan, (1981: 3-20).

9 Ibid., p.4.

10 The Human Capital school provides an example of a body of theory which recognises pre-market segmentation whilst not seeking explicitly to remedy it.

${ }^{11}$ Ryan, op.cit., p.5.

12 See, for example Piore (1975: 125-150).

${ }^{13}$ Edwards et.al, ibid., p.xvi.

14 Adnett (1989: 56).

15 Wachter (1974: 655).

16 This was due to matters of sheer practicality - in order that the questionnaires were confidential and anonymous, respondents were randomly drawn from union mailing lists.

${ }^{17}$ Supervisors are omitted because they need not strictly correlate to any given skill level.

18 Bowie (1983: 82).

\section{Author}

Chan Dixon is a Doctoral candidate in the Politics Department at Auckland University, Private Bag 92019, Auckland. 